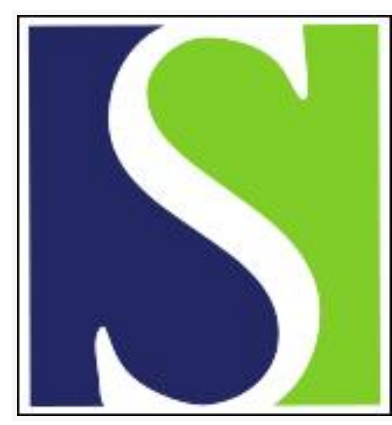

Scand J Work Environ Health 1980;6(1):33-39

https://doi.org/10.5271/sjweh.2638

Issue date: Mar 1980

Clinical neurological findings among car painters exposed to a mixture of organic solvents.

by Husman K, Karli P

Key terms: affection; car painter; central nervous system; clinical neurological finding; exposure; impairment; neurological finding; neurotoxicity; organic solvent; peripheral nervous system; sense of vibration; vibration

This article in PubMed: www.ncbi.nlm.nih.gov/pubmed/6247761

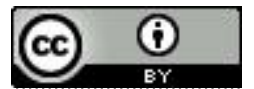




\title{
Clinical neurological findings among car painters exposed to a mixture of organic solvents
}

\author{
by Kaj Husman, MD, ${ }^{1}$ Pauli Karli, MD ${ }^{2}$
}

\begin{abstract}
HUSMAN K, KARLI P. Clinical neurological findings among car painters exposed to a mixture of organic solvents. Scand $j$ work environ health 6 (1980) 33-39. A full clinical neurological examination was used to study the possible effects of long-term exposure to low concentrations of mixtures of organic solvents on the nervous system. The exposed group consisted of 102 male car painters and the referents of 102 age- and sexmatched locomotive engineers and assistants. The psychoorganic syndrome, a decrease in the sense of light touch and pain, and an increase in the vibration threshold were more frequent among the car painters than among the referents, and the observed differences of these frequencies were statistically significant. The sense of vibration had been affected in the lower extremities of 65 of the 102 car painters and in 25 of the referents. Sensory functions seem to be the most vulnerable part of the nervous system of workers chronically exposed to different organic solvents.
\end{abstract}

Key terms: affection of the central and peripheral nervous systems, impairment in the sense of vibration, neurotoxicity, organic solvents.

It is well known that nervous system damage can occur after exposure to organic solvents (4). Peripheral neuropathy has recently been studied extensively in typical work environments $(1,5,7,14)$, in "sniffers" $(8,17,18,23)$, and in experimental animals $(21,27,29,30)$. In such studies the causes of neuropathy have been n-hexane $(14,27,33)$, trichloroethylene (7), and methyl butyl ketone $(1,21,29,31)$. For "sniffers" the etiologic agents have often been referred to only as "volatile hydrocarbons" $(22,32)$. The exposures of "sniffers" have been high.

1 Kuopio Regional Institute of Occupational Health, Kuopio, Finland.

2 Department of Neurology, University Central Hospital, Helsinki, and Institute of National Social Insurance, Helsinki, Finland.

Reprint requests to: Dr Kaj Husman, Kuopio Regional Institute of Occupational Health, Kauppakatu 59-61, SF-70100 Kuopio 10, Finland.
Permanent central nervous system (CNS) damage, eg, cerebral and cerebellar dysfunction after the deliberate inhalation of toluene has also been described in one man $(8,17)$. Schaumberg \& Spencer $(25)$ showed that 2,5 hexanedione, the principal metabolite of the industrial solvents n-hexane and methyl butyl ketone, causes brain lesions in experimental animals, and they suggested that prolonged, low-level exposure to hydrocarbons in the work environment may cause premature deterioration in areas of the human brain vital for perception and behavior.

An extensive investigation has been carried out with the objective of studying the effects of long-term exposure to low concentrations of organic solvent mixtures on the central and peripheral nervous systems (CNS and PNS, respectively). Other phases of the study have been published elsewhere $(10,15,24,28)$. The goal of this part of the study was to compare the prev- 
alences of neurological signs among exposed persons and referents with the aim of identifying the parts of a full clinical neurological examination which would differentiate best between exposed persons and referents.

\section{Material and methods}

\section{Subjects}

The subjects comprised a sample of 102 male car painters from 27 car repair garages in Helsinki in 1974. They were selected from all active car painters in Helsinki $(N=166)$ by stratified sampling so that subjects with different exposure times were as evenly represented as possible (14). The exposure of the car painters to organic solvents was about one-third of the respective Finnish administrative threshold limit values (TLVs), which are close to those of the American Conference of Governmental Industrial Hygienists (2). The exposure has been described in detail in another report (15). The length of exposure ranged from 1 to 40 a (mean 14.8, SD 8.5), and the age from 20 to 65 a (mean 35, SD 11).

The reference group was chosen from locomotive engineers and assistants of the Finnish State Railways. Half of the reference group consisted of engineers and the other half of assistants. They were sexand age-matched $( \pm 2$ a) with the exposed subjects. There were no engineers older than 54 available, however, because their retirement age is 55 a. Irregular shift work and mental stress are the most important factors of railroad work (13) which might have an effect on the occurrence of subjective symptoms among the referents.

Workers with a history of diabetes, epilepsy and cerebral contusion were not excluded from the study; the reasons for inclusion have been discussed in another paper (15).

\section{Methods}

The neurological examinations were performed by the same neurologist (PK), who was unavare of whether or not the subject was exposed. The subject was told before the examination not to tell the neurologist his occupation, and the neu- rologist's interview did not include the subject's work history.

A full neurological examination was carried out in a uniform manner, it included the estimation of mental changes, the examination of cranial nerves, and the testing of motor functions, reflexes and sensory functions.

In this study changes indicating impaired judgement, comprehension, memory attention, speed of response, and the ability to give relevant answers to simple questions (which suggest a diffuse impairment of cerebral function) are called the psychoorganic syndrome. According to the occurrence of these features the neurologist classified the subjects into two groups, either with or without the psychoorganic syndrome.

The functions of all cranial nerves were examined separately, and the findings were registered.

The examination of the motor system included the testing of the strength of the muscle groups in the extremities. The strength of the muscle groups was graded from 0 to 5, and atrophy and fasciculations of the muscles were recorded. The subjects' posture, their coordinated automatic movements, their ability to walk along a straight line, and their ability to make rapid turning movements were observed and recorded as normal, moderately ataxic, or severely ataxic. The Romberg test was applied according to the standard method, and the findings were classified as normal, moderately pathological or markedly pathological.

Rapidly alternating movements of the fingers were observed, and the findings were classified as normal, moderately pathological, or markedly pathological. Coordination was examined by the finger-tonose and finger-to-finger tests in the upper extremities, and by the toe-finger and heel-to-shin tests in the lower extremities. The findings were recorded as being normal, dysmetric, or ataxic. Intentional, postural and static tremor was recorded in the upper and lower extremities.

Deep reflexes of the biceps, triceps, finger flexors, quadriceps femoral, and gastrocnemius soleus muscles were examined with the subject in a recumbent position, and the response elicited was graded from 0 to 3 . Superficial reflexes, including ab- 
dominal reflexes, were graded as absent or normal, and the plantar response (Babinski's sign) was graded as normal or pathological.

The sense of light touch was tested with a wisp of cotton at the neck, the trunk, the arms and hands, and the hands (including also the peripheral distribution of the radial, medial and ulnar nerves). The lower extremities were examined with the same method. Comparisons were made between the left and the right side and between the proximal and distal parts of the extremities; the findings were graded as normal, changed, or markedly impaired.

The sense of pain was examined with a "tailor's marking wheel" (pricking wheel) at the same areas as the sense of light touch, and the findings were graded as normal, changed, or markedly impaired. In addition it was estimated whether the changed or markedly impaired sensation had segmental or peripheral distribution. Thermal sense was not examined because the afferent pathways of pain and thermal sense are closely connected.

The sense of vibration of all the subjects was tested with the same tuning-fork, which had a controlled frequency of 109 $\mathrm{Hz}$ and a long duration of vibration. The branches of the tuning-fork were pressed together to touch each other and were then suddenly let loose so that the fork vibrated maximally. The vibrating tuning-fork was applied to the point to be examined for 2 s. This procedure was carried out repeatedly at 1-s intervals until the vibration threshold was achieved. The vibration threshold can be measured by this method with an accuracy of $2 \mathrm{~s}$ (3).

The sense of vibration was examined at the extensor side of the second phalanx of the hallux, at the outer malleoli, and at the middle of the tibia and the tibial tuberosity. In the upper extremities the sense of vibration was tested at the extensor side of the second phalanx of the middle fingers, at the wrists, and at the middle of the radius and elbows. The following classification of impairment in the sense of vibration was used: normal, ie, $\geq 11$ s (class 0 ), slightly pathological, 6$10 \mathrm{~s}$ (class 1), and clearly pathological $\leq 5 \mathrm{~s}$ (class 2). The values considered pathological in this study are below the usual ranges (3) and therefore should account for for the fact that the sense of vibration weakens with age (3).

Postural sensation was examined as the subjects stood with their arms outstretched and eyes closed; the perception of passive movement was tested in their fingers and toes. The findings were classified as lacking, unsure, or normal.

At the end of the complete neurological examination the examiner summarized the main findings as psychoorganic syndrome, cerebellar and extrapyramidal findings, or involvement of cranial nerves. Other sensory, motor, and mixed sensory motor findings were also summarized (table 1) and classified as normal, slightly pathological or clearly pathological.

\section{Results}

A summary of the neurological findings appears in table 1 . Statistically significant differences between the exposed subjects and the referents occurred for the psychoorganic syndrome and sensory findings.

Forty-three per cent of the car painters and $17 \%$ of the referents showed sensory abnormalities.

The effect of age was eliminated by means of a pairwise comparison; thereafter the differences between the groups became even more pronounced. In 12 of the total 102 pairs the findings for psychoorganic syndrome were more pathological for the car painter than his referent (table 1). In 36 of 101 pairs the exposed subject had more pathological sensory findings than his referent (table 1).

Only few pathological findings appeared, and no statistically significant differences, between the groups with respect to the cerebellar and extrapyramidal system, the cranial nerves, and peripheral motor and sensorimotor functions.

Pathological findings (changed or markedly impaired) for the sense of light touch occurred more frequently in the exposed group only in regard to both hands, and not in the lower extremities or the trunk. In order to avoid the possible effect of traumatic lesions of peripheral nerves (eg, entrapment neuropathy), we compared only the findings of the left extremities. In 19 of 96 pairs the exposed subject had damage in the sensation of light touch in 
his left hand more often than his referent, and only in two pairs was the situation reversed (table 2).

In the pairwise comparison, 16 car painters had a worse sense of pain in their left hand than their referent. There was only one referent with a worse sense of pain than his pair (table 3 ).

There were few pathological findings in the lower extremities and the trunk, and no differences were found between the exposed group and the referents.

The sense of vibration was affected in the peripheral areas of both the upper and the lower extremities more often in the exposed group than among the referents. The differences between the groups were more pronounced in the lower than in the upper extremities (table 4). Sixty-four per cent of the painters and $25 \%$ of the engineers and assistants had slightly or clearly pathological findings with respect to the sense of vibration in their left foot.

In the pairwise comparison the exposed subjects showed more pathological findings than the referents for the sense of vibration in the left hand in 17 pairs and in the left foot in 45 pairs (table 4).

\section{Discussion}

Dizziness, unusual tiredness, concentration difficulties, and impaired memory are the most commonly reported symptoms of workers who are chronically exposed to different organic solvents $(9,11,12,15,16$,

Table 1. Summary of the findings from the clinical neurological examinations of the exposed subjects and the referents. $(N=102$ pairs $a)$

\begin{tabular}{|c|c|c|c|c|c|c|c|c|c|c|}
\hline \multirow{2}{*}{ Findings } & \multicolumn{3}{|c|}{$\begin{array}{l}\text { Exposed } \\
\text { subjects } b\end{array}$} & \multicolumn{3}{|c|}{ Referents b } & \multirow{2}{*}{$\begin{array}{l}\text { Observation } \\
\text { missing }\end{array}$} & \multicolumn{3}{|c|}{$\begin{array}{l}\text { Differences } \\
\text { in pairs c }\end{array}$} \\
\hline & 0 & 1 & 2 & 0 & 1 & 2 & & - & + & $2 p d$ \\
\hline Psychoorganic syndrome & 89 & 9 & 4 & 100 & 2 & 0 & - & 1 & 12 & $<0.01$ \\
\hline $\begin{array}{l}\text { Cerebellar and extra- } \\
\text { pyramidal findings }\end{array}$ & 94 & 7 & 1 & 99 & 3 & 0 & 一 & 3 & 8 & NS \\
\hline $\begin{array}{l}\text { Findings in cranial } \\
\text { nerves }\end{array}$ & 73 & 20 & 8 & 78 & 18 & 5 & 1 & 18 & 21 & \\
\hline $\begin{array}{l}\text { Sensory findings } \\
\text { (sense of vibration ex- } \\
\text { cluded, see table 4) }\end{array}$ & 57 & 44 & 0 & 84 & 16 & 1 & 1 & 10 & 36 & $<0.001$ \\
\hline $\begin{array}{l}\text { Motor findings } \\
\text { (peripheral motor nerves) }\end{array}$ & 100 & 1 & 0 & 99 & 1 & 1 & 1 & 2 & 1 & NS \\
\hline $\begin{array}{l}\text { Sensorimotor } \\
\text { findings }\end{array}$ & 101 & 1 & 0 & 101 & 0 & 1 & - & 1 & 1 & \\
\hline
\end{tabular}

a Any pair with one or more missing observations was omitted from the statistical calculations.

b $0=$ normal, $1=$ slightly pathological, $2=$ clearly pathological.

c $+=$ the exposed subject had "worse" findings than his pair, $-=$ the referent had "worse" findings than his pair.

d Sign test; NS = not significant.

Table 2. Light touch in the left hand of the exposed subjects and the referents. ( $N=102$ a)

\begin{tabular}{|c|c|c|c|c|c|c|c|c|c|c|}
\hline \multirow{2}{*}{ Finding } & \multicolumn{3}{|c|}{$\begin{array}{c}\text { Exposed } \\
\text { subjects b }\end{array}$} & \multicolumn{3}{|c|}{ Referents $\mathbf{b}$} & \multirow{2}{*}{$\begin{array}{l}\text { Observation } \\
\text { missing }\end{array}$} & \multicolumn{3}{|c|}{$\begin{array}{l}\text { Differences } \\
\text { in pairs } c\end{array}$} \\
\hline & 0 & 1 & 2 & 0 & 1 & 2 & & - & + & $2 p d$ \\
\hline In the left hand & 75 & 7 & 14 & 93 & 1 & 2 & 6 & 2 & 19 & $<0.001$ \\
\hline
\end{tabular}

a Any pair with one or more missing observations was omitted from the statistical calculation.

b $0=$ normal, 1 = changed, $2=$ markedly impaired.

c $+=$ the exposed subject had a "worse" finding than his pair, $-=$ the referent had a "worse" finding than his pair.

d Sign test. 
$19,20)$. These symptoms suggest that longterm exposure to organic solvents has a toxic effect on the CNS.

The diffuse cerebral findings, including the psychoorganic features, registered by the examiner in the present study are compatible with the results of the earlier neuropsychological examination (10) and subjective symptoms (15) of this project. These findings indicate a slight cerebral lesion.

Schaumburg \& Spencer (25) exposed cats to a metabolite of n-hexane, 2,5-hexanedione, and found lesions in cerebellar tracts. Trichloroethylene has been reported to cause lesions in optic and trigeminal nerves (4), but there are no reports in the literature of cranial nerve involvements caused by exposure to other organic solvents. However, evidence of cranial nerve damage was rare in our study. Because the car painters had symptoms, eg, dizziness and a drunken feeling (15), which hint towards a cerebellar effect of organic solvents, the lack of cerebellar and extrapyramidal signs was an interesting finding.
The sense of vibration is a composite sensation comprising touch and rapid alterations of deep-pressure sense. The conduction depends on both the cutaneous and the deep afferent fibers which ascend in the dorsal columns of the spinal cord. Therefore the sense of vibration is rarely affected by lesions of single nerves, but tends to be disturbed in cases of polyneuropathy and disease of the dorsal columns, the medial lemniscus, and the thalamus. The senses of vibration and posture are usually damaged together, but that of vibration may be affected disproportionately.

In the present study the main sensory deficit was that of the sense of vibration, especially in the lower extremities. These findings reflect a vulnerability in this sense. The lesion may occur either in the long sensory fibers or in selected tracts of the CNS, especially in the spinal cord.

Impairment of light touch and pricking pain reached a statistically significant level in the exposed group in comparison to the referents. This result suggests peripheral neuropathy in the long sensory fibers.

Table 3. Sense of pain in the left hand of the exposed subjects and the referents. $(N=102$ a)

\begin{tabular}{|c|c|c|c|c|c|c|c|c|c|c|}
\hline \multirow{2}{*}{ Finding } & \multicolumn{3}{|c|}{$\begin{array}{l}\text { Exposed } \\
\text { subjects b }\end{array}$} & \multicolumn{3}{|c|}{ Referents b } & \multirow{2}{*}{$\begin{array}{l}\text { Observation } \\
\text { missing }\end{array}$} & \multicolumn{3}{|c|}{$\begin{array}{l}\text { Differences } \\
\text { in pairs } c\end{array}$} \\
\hline & 0 & 1 & 2 & 0 & 1 & $\overline{2}$ & & - & + & $2 p d$ \\
\hline In the left hand & 78 & 6 & 12 & 93 & 1 & 2 & 6 & 1 & 16 & $<0.001$ \\
\hline
\end{tabular}

a Any pair with one or more missing observations was omitted from the statistical calculation.

b $0=$ normal, $1=$ changed, $2=$ markedly impaired.

c $+=$ the exposed subject had a "worse" finding than his pair, $-=$ the referent had a "worse" finding than his pair.

d Sign test.

Table 4. Sense of vibration in the left hand and left foot of the exposed subjects and the referents. $(\mathrm{N}=102 \mathrm{a})$

\begin{tabular}{|c|c|c|c|c|c|c|c|c|c|c|}
\hline \multirow{2}{*}{ Finding } & \multicolumn{3}{|c|}{$\begin{array}{c}\text { Exposed } \\
\text { subjects b }\end{array}$} & \multicolumn{3}{|c|}{ Referents $b$} & \multirow{2}{*}{$\begin{array}{l}\text { Observation } \\
\text { missing }\end{array}$} & \multicolumn{3}{|c|}{$\begin{array}{l}\text { Differences } \\
\text { in pairs } c\end{array}$} \\
\hline & 0 & 1 & 2 & 0 & 1 & 2 & & - & + & $2 p d$ \\
\hline $\begin{array}{l}\text { In the left hand } \\
\text { In the left foot }\end{array}$ & $\begin{array}{l}78 \\
37\end{array}$ & $\begin{array}{l}16 \\
43\end{array}$ & $\begin{array}{r}4 \\
22\end{array}$ & $\begin{array}{l}90 \\
77\end{array}$ & $\begin{array}{r}5 \\
17\end{array}$ & $\begin{array}{l}3 \\
8\end{array}$ & -4 & $\begin{array}{l}5 \\
5\end{array}$ & $\begin{array}{l}17 \\
45\end{array}$ & $\begin{array}{l}<0.05 \\
<0.001\end{array}$ \\
\hline
\end{tabular}

a Any pair with one or more missing observations was omitted from the statistical calculation.

b $0=$ normal, $1=$ slightly pathological, $2=$ clearly pathological.

$c+=$ the exposed subject had a "worse" finding than his pair, $-=$ the referent had a "worse" finding than his pair.

d Sign test. 
In contrast to the results reported by Yamamura (33), Cianchetti et al (5), Mendell et al (21), and Allen et al (1), no signs were found that indicated lesions in the peripheral motor system. In the other studies the exposure was n-hexane and/or methyl butyl ketone, and the level of exposure was higher than in our investigation.

The car painters were not exposed to n-hexane or methyl n-butyl ketone, and their exposure to organic solvents was only one-third of the current Finnish administrative TLVs - they were not ill in the clinical sense. Although the exposure was low, we found clear signs of CNS and PNS lesions more often among the car painters than among the referents. The differences were statistically significant and suggest that the lesions were caused by exposure to organic solvents.

In a recent Swedish study (6) the authors observed the same type of lesions in the CNS and PNS although the exposure had been even lower than in our study. In that investigation the exposed subjects had an increased vibration threshold more frequently in their lower extremities (tibial), as we observed in our study. Therefore the sensory functions may be the most vulnerable part of the nervous system in workers who are chronically exposed to organic solvents. According to Schaumburg \& Spencer (26) light touch, pricking pain, and temperature discrimination are more decreased than the sense of vibration in toxic occupational neuropathy (26). Because pathological findings in the sense of vibration occurred more frequently (65/ 102) (table 4) than all of the other findings of this study $(12,15,24,28)$, this sense seems to be the most sensitive function to suffer in long-term exposure to organic solvents, at least in terms of the functions studied and the methods used in the present investigation.

\section{Acknowledgments}

We wish to thank E Järvinen, MSc, and Ms P Fahlström for carrying out the statistical analyses.

The study has been financially supported by the Yrjö Jahnsson Foundation.

\section{References}

1. Allen N, Mendell JR, Billmaier DJ, Fontaine EE, O'Neill J. Toxic polyneuropathy due to methyl n-butyl ketone. Arch neurol 32 (1975) 209-218.

2. American Conference of Governmental Industrial Hygienists. Threshold limit values of airborne contaminants adopted by American Conference of Governmental Industrial Hygienists for 1971. Cincinnati, $\mathrm{OH} 1971$.

3. Björkenheim G. Neurological changes in pernicious tapeworm anaemia. Acta med scand suppl 260 (1951).

4. Browning E. Toxicity and metabolism of industrial solvents. Elsevier, Amsterdam 1965.

5. Cianchetti C, Abbritti G, Perticoni G, Siracusa $A$, Currade $F$. Toxic polyneuropathy of shoe-industry workers. J neurol neurosurg psychiatry 39 (1976) 115I-1161.

6. Elofsson S-A, Gamberale F, Hindmarsch $\mathrm{T}$, Iregren A, Isaksson A, Johnsson I, Knave B, Lydahl E, Mindus P, Persson H, Philipson B, Steby M, Struwe G, Söderman E, Wennberg A, Widen L. En epidemiologisk undersökning av yrkesmässigt exponerade bil- och industrilackerade. Läkartidningen 46 (1979) 4127-4148.

7. Feldman RG, Mayer RM, Taub A. Evidence for peripheral neurotoxic effect of trichloroethylene. Neurology 20 (1970) 599-608.

8. Grabski DA. Toluene sniffing producing cerebellar degeneration: Case reports. Am j psychiatry 118 (1961) 461-462.

9. Gregersen P, Mikkelsen S, Klausen H, Døssing $M$, Nielsen $H$, Thygelsen P. Et kronisk cerebralt malersyndrom. Ugeskr laeg 140 (1978) 1638-1644.

10. Hänninen H, Eskelinen K, Husman K, Nurminen M. Behavioral effects of long-term exposure to a mixture of organic solvents. Scand j work environ health 4 (1976) 240255.

11. Härkönen $H$. Relationship of symptoms to occupational styrene exposure and to the findings of electroencephalographic and psychological examinations. Int arch occup environ 40 (1977) 1-9.

12. Hane $M$, Axelson $O$, Blume J, Hogstedt $C$, Sundell L, Ydreborg B. Psychological function changes among house painters. Scand j work environ health 3 (1977) 91-99.

13. Heino Mr, Ketola $R$, Mäkelä $P$, Mäkinen $R$, Niemelä R, Starck J, Partanen T. Work conditions and health of locomotive engineers. Scand $j$ work environ health 4 (1978): suppl 3, 3-14.

14. Herskowitz A, Ishii N, Schaumburg J. N-Hexane neuropathy: A syndrome occurring as a result of industrial exposure. New engl j med 285 (1971) 82-85.

15. Husman K. Symptoms among car painters with long-term exposure to a mixture of organic solvents. Scand $j$ work environ health 6 (1980)

16. Knave B, Olson BA, Elofsson S, Gamberale $F$, Isaksson $A$, Mindus $P$, Persson $\mathrm{HE}$, 
Struwe G, Wennberg A, Westerholm P. Long-term exposure to jet fuel. Scand $j$ work environ health 4 (1978) $19-45$.

17. Knox JW, Nelson JR. Permanent encephalopathy from toluene inhalation. New engl j med 275 (1966) 1494-1496.

18. Korobkin R, Asbury AK, Sumner AJ, Nielsen SL. Glue-sniffing neuropathy, Arch neurol 32 (1975) 158-162.

19. Lajer $M$. Investigation of symptoms in house painters at their work sites. Ugeskr laeg 138 (1976) 1225-1230.

20. Lindström $K$. Liuotinainealtistuksen vaikutuksista psyykkiseen suorituskykyyn. Institute of Occupational Health, Helsinki 1972. (Työterveyslaitoksen tutkimuksia 73).

21. Mendell JR, Saida K, Ganansia MF, Jackson DB, Weiss H, Gardier RW, Chrisman C, Allen N, Couri D, O'Neill J, Marks B, Hetland L. Toxic polyneuropathy produced by methyl n-buthyl ketone. Science 185 (1974) 787-789.

22. Prockop LD. Multifocal nervous system damage from inhalation of volatile hydrocarbons. J occup med 19 (1977) 139-140.

23. Prockop LD, Malcolm A, Tison J. "Huffer's" neuropathy. J am med assoc 229 (1974) 1083-1084.

24. Raitta C, Husman $\mathrm{K}$, Tossavainen A. Lens changes in car painters exposed to a mixture of organic solvents. Albrecht von Graefes Arch Klin Exp Ophthalmol 200 (1976) 149-156.

25. Schaumburg $\mathrm{HH}$, Spencer P. Environmental hydrocarbons produce degeneration in cat hypothalamus and optic tract. Science 4325 (1978) 199-200.

26. Schaumburg HH, Spencer PS. The neurology and neuropathology of the occupational neuropathies. J occup med 18 (1976) $739-743$.

27. Schaumburg HH, Spencer PS. Degeneration in central and peripheral nervous system produced by pure n-hexane: An experimental study. Brain 99 (1976) 183-192.

28. Seppäläinen AM, Husman K, Mårtenson C. Neurophysiological effects of long-term exposure to a mixture of organic solvents. Scand $\mathrm{j}$ work environ health 4 (1978) 304 -314 .

29. Spencer PS, Schaumburg HH. Experimental neuropathy produced by 2,5-hexanedione - A major metabolite of the neurotoxic industrial solvent methyl n-butyl ketone. J neurol neurosurg psychiatry 38 (1975) $771-775$.

30. Spencer PS, Schaumburg HH. Ultrastructural studies of the dying-back process: III. The evolution of experimental peripheral giant axonal degeneration. $\mathrm{J}$. neuropathol exp neurol 36 (1977) 276-299.

31. Spencer PS, Schaumburg HH, Raleigh RL, Terhaar CJ. Nervous system degeneration produced by industrial solvent methyl n-buthyl ketone. Arch neurol 32 (1975) 219 -222 .

32. Wyse DG. Deliberate inhalation of volatile hydrocarbons: A review. Can med assoc $j$ 108 (1973) $71-74$.

33. Yamamura Y. n-Hexane polyneuropathy. Folia psychiatr neurol jpn 23 (1969) 45-47. 